Virginia Commonwealth University vCU Scholars Compass

2006

\title{
Optical susceptibilities of supported indium tin oxide thin films
}

Jonathan L. Humphrey

Virginia Commonwealth University

Darius Kuciauskas

Virginia Commonwealth University, Rowan University

Follow this and additional works at: http://scholarscompass.vcu.edu/chem_pubs

Part of the Chemistry Commons

Humphrey, J. L., and Kuciauskas, D. Optical susceptibilities of supported indium tin oxide thin films. Journal of Applied Physics, 100, 113123 (2006). Copyright (C) 2006 American Institute of Physics.

\section{Downloaded from}

http://scholarscompass.vcu.edu/chem_pubs/17

This Article is brought to you for free and open access by the Dept. of Chemistry at VCU Scholars Compass. It has been accepted for inclusion in Chemistry Publications by an authorized administrator of VCU Scholars Compass. For more information, please contact libcompass@vcu.edu. 


\title{
Optical susceptibilities of supported indium tin oxide thin films
}

\author{
Jonathan L. Humphrey \\ Department of Chemistry, Virginia Commonwealth University, 1001 West Main Street, Richmond, \\ Virginia 23284-2006 \\ Darius Kuciauskas ${ }^{a}$ \\ Department of Chemistry, Virginia Commonwealth University, 1001 West Main Street, Richmond, \\ Virginia 23284-2006 and Department of Chemistry and Biochemistry, Rowan University, 201 Mullica Hill \\ Road, Glassboro, New Jersey 08028
}

(Received 19 May 2006; accepted 14 September 2006; published online 15 December 2006)

The third-order nonlinear optical susceptibility of indium tin oxide (ITO) thin films on glass substrates, $\chi_{\text {ITO }}^{(3)}$, was determined in the near-IR spectral region using degenerate four wave mixing (DFWM) spectroscopy with 100 fs laser pulses. A DFWM method for measuring thin films on thick substrates was refined for the characterization of films less than $100 \mathrm{~nm}$ thick and applied to $\sim 25 \mathrm{~nm}$ thick ITO films. It was found that $\chi^{(3)}$ ITO is purely electronic at $900-1300 \mathrm{~nm}$ $\left(11000-7700 \mathrm{~cm}^{-1}\right)$ and has a value of $(2.16 \pm 0.18) \times 10^{-18} \mathrm{~m}^{2} \mathrm{~V}^{-2}$. The $\chi^{(3)}$ ITO value reaches $(3.36 \pm 0.28) \times 10^{-18} \mathrm{~m}^{2} \mathrm{~V}^{-2}$ at $1500 \mathrm{~nm}\left(6700 \mathrm{~cm}^{-1}\right)$ due to two-photon absorption by free carriers (electrons). Ultrafast electron relaxation was also observed. The $\sim 100$ fs lifetime of this process could reflect electron scattering in the conduction band. (C) 2006 American Institute of Physics.

[DOI: $10.1063 / 1.2392995]$

\section{INTRODUCTION}

Indium tin oxide (ITO) is a conductive material that transmits visible light but reflects infrared radiation. ${ }^{1}$ A number of techniques have been used to grow nanometer to micrometer thick films of ITO on transparent substrates. ${ }^{2-4}$ This processability has allowed the unique combination of electrical and optical properties of ITO to be applied to solar cells, heat-reflecting mirrors, and antireflective coatings. ${ }^{5}$ Layers of functionalized materials can be added to ITO thin films by physical (i.e., spin coating or vapor deposition) or chemical (i.e., electropolymerization of porphyrins) methods. ${ }^{6-11}$ This versatility has resulted in ITO being used to prepare electroluminescent devices, flat panel displays, and light emitting diodes (LEDs). ${ }^{12-16}$

The electrical and optical properties that have made ITO useful in a broad array of technologies are a consequence of the relative energies of the valence and conduction bands. ITO is a highly degenerate $n$ type, wide band gap $(3.5-4.3 \mathrm{eV})$ semiconductor with an electrical resistivity of $2-4 \times 10^{-4} \Omega \mathrm{cm}^{17-19}$ The low resistivity is the result of a degeneracy created during film formation by oxygen vacancies and substitutional tin dopants. As a result, the Fermi level is above the conduction band edge. This ordering results in a conductive material with a carrier concentration in the range of $10^{20}-10^{21} \mathrm{~cm}^{-3} \cdot{ }^{17,18}$ These free carriers are responsible for the transition of ITO from a transparent to a reflective material.

ITO's shift from a transparent to reflective material occurs over a broad range of wavelengths. ${ }^{17}$ The free carrier absorption reaches a maximum when the transmission $T$ and the reflectance $R$ have the same value. ${ }^{17}$ This spectral feature is called the plasma frequency $\omega_{p}{ }^{20}$ The plasma frequency of

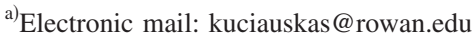

ITO is usually found in the near IR. The value of $\omega_{p}$ is determined by the conditions used in film preparation. ${ }^{17,19} \mathrm{~A}$ simple Drude model describes free carrier effects on the optical and electric properties of ITO. ${ }^{5}$ According to this model, $\omega_{p}$ depends on the concentration of free carriers $N,{ }^{17}$

$$
\omega_{p}^{2}=\frac{N e^{2}}{\varepsilon_{0} \varepsilon_{\infty} m_{e}^{*} c^{2}},
$$

where $e$ is the electron charge; $\varepsilon_{0}$ and $\varepsilon_{\infty}$ are the dielectric constants of the medium and free space, respectively; $m_{e}{ }^{*}$ is the effective mass of the charge carrier; and $c$ is the speed of light.

The inherent presence of free electrons in the crystal lattice of ITO could make it useful in the development of photonic devices. We recently characterized the two-photon absorption and nonlinear refraction properties of electropolymerized metalloporphyrin films on ITO substrates. ${ }^{21,22}$ Many photonic devices are based on nonlinear optical effects, ${ }^{23}$ yet the nonlinear optical properties of ITO films have not been characterized to date. The physical mechanisms that give rise to nonlinear optical effects are similar to those that contribute to "simpler" optical properties such as absorbance, reflectance, and transmittance. ${ }^{23}$ Nonlinear susceptibilities, which describe the efficiency of processes such as two-photon absorption and nonlinear refraction, depend on the properties of the ground and excited states. ${ }^{23}$ In this paper, we analyze the third-order nonlinear optical susceptibility $\chi^{(3)}$ ITO of ITO films in a near IR wavelength region important for telecommunications and consider contributions of the plasma frequency and free electron absorption to the nonlinear spectra. 


\section{MATERIALS AND METHODS}

ITO/glass slides (ITO coated Corning 1737 aluminosilicate glass) were purchased from Delta Technologies. The glass substrate was $0.7 \mathrm{~mm}$ thick, and the ITO films had a reported resistance of $100 \Omega / \square$. The thickness of the ITO film, $\sim 20-30 \mathrm{~nm}$, was determined using atomic force microscopy (Nanoscope IIIA multimode, Digital Instruments). The tapping mode of the AFM was used.

The ITO coated glass slide was cleaned with water, isopropanol, and acetone by sonication in an ultrasonic cleaner for $5 \mathrm{~min}$ in each solvent. The slide was dried with a stream of nitrogen. In addition to ITO coated substrates, the glass substrates from which the ITO layer was removed were also studied. The ITO layer was removed by placing the coated slide in an aqueous solution of $20 \% \mathrm{HCl}$ and $5 \% \mathrm{HNO}_{3}$ for $10 \mathrm{~min}$. A $1 \mathrm{~mm}$ thick silica window (purchased from Thorlabs) was used as a reference in the degenerate four wave mixing (DFWM) experiments. The transmittance and reflectance spectra were measured with a PerkinElmer Lambda 950 UV-Vis-NIR spectrometer.

DFWM spectroscopy. The "forward box" DFWM geometry has been described previously. ${ }^{24} \mathrm{~A}$ femtosecond optical parametric amplifier (OPA TOPAS, Quantronix/Light Conversion) was used to generate pulses for excitation at $900-1500 \mathrm{~nm}\left(11000-6700 \mathrm{~cm}^{-1}\right)$. The OPA was pumped by a regeneratively amplified Ti:sapphire laser system (Spitfire, Spectra Physics). In a four wave mixing experiment, the overlap of three laser beams with intensities $I_{1}, I_{2}$, and $I_{3}$ in the sample gives rise to a signal beam $I_{4}$. Beams $I_{1}-I_{4}$ were $s$ polarized. Signal $I_{4}$ is proportional to the square of the material's third-order nonlinear susceptibility $\chi^{(3)},{ }^{23}$

$$
I_{4}=\left[\chi^{(3)}\right]^{2} \frac{l^{2}}{n^{4}} I_{1} I_{2} I_{3},
$$

where $l$ is the thickness of the material and $n$ is the refractive index. According to Eq. (2), the DFWM signal should have a cubic intensity dependence. This dependence was verified in all of the experiments. The typical excitation intensity used in DFWM experiments $\left(I_{1}+I_{2}+I_{3}\right)$ was $14.5 \mathrm{GW} \mathrm{cm}^{-2}$.

DFWM spectroscopy of thin supported films. In DFWM studies of thin films on thick substrates, the optical signal contains contributions from both the film and the substrate. These contributions can be separated using a method based on the different phase-matching conditions of the thin film and thick substrate. ${ }^{25-28}$ As shown in Fig. 1, the phasematched signal $I_{4}$ propagates in a direction that satisfies geometric (phase-matching) conditions defined as $\boldsymbol{k}_{1}+\boldsymbol{k}_{2}=\boldsymbol{k}_{3}$ $+\boldsymbol{k}_{4}$, where $\boldsymbol{k}_{i}$ are the wave vectors of the corresponding optical beams $i\left(\boldsymbol{k}_{4}\right.$ is a wave vector of an optical signal, and $\boldsymbol{k}_{1}-\boldsymbol{k}_{3}$ are the wave vectors of laser beams). ${ }^{27}$ Signals that do not satisfy the phase-matching conditions, $I_{5}$ and $I_{6}$, are also generated during the experiment. The propagation direction of these beams is indicated in Fig. 1. The intensity of these additional signals relative to that of the fully phase-matched signal $I_{4}$ depends on the thickness of the material as described below.

Strokhendl et al. showed that the intensities of $I_{4}, I_{5}$, and $I_{6}$ can be determined by solving Maxwell's equations for

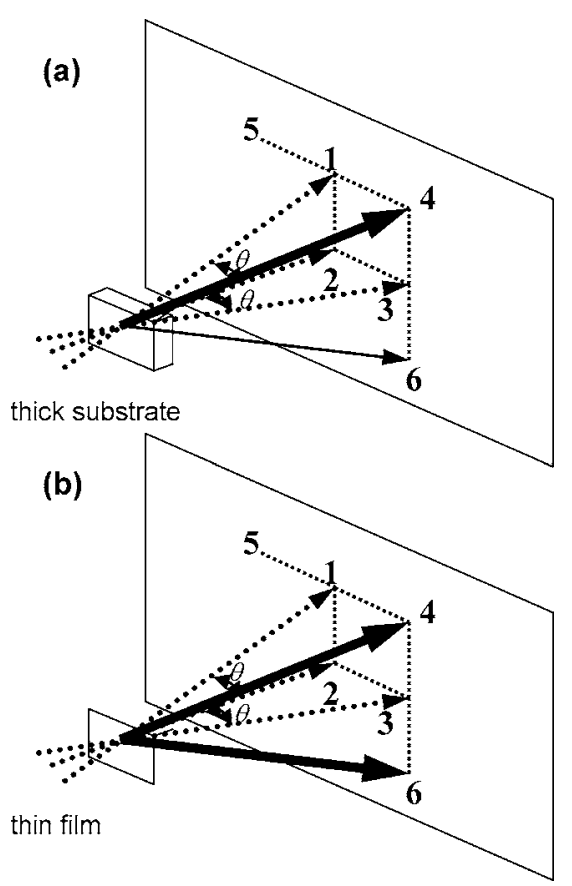

FIG. 1. Experimental geometry for DFWM measurements that is based on different phase-matching conditions for substrates and thin films.

these signals. ${ }^{27}$ According to this model, the intensity of the non-phase-matched signals $I_{6}$ and $I_{5}$ can be expressed as

$$
I_{5}=I_{6}=F\left[\chi^{(3)}\right]^{2} \frac{l^{2}}{n^{4}} I_{1} I_{2} I_{3} .
$$

This expression is identical to that of Eq. (2), except that the phase-matching effects are described by the inclusion of factor $F$. Factor $F$ is

$$
F=\left[\frac{\sin (x)}{x}\right]^{2} \text { where } x=\frac{\theta^{2} \omega l}{2 n c},
$$

$\theta$ is the angle between the optical beams, $\omega$ is the optical frequency used in the experiment, and $c$ is the speed of light. The magnitude of $F$ is largely determined by the thickness $l$. Films from nanometer to micrometer thickness will have $F$ $\approx 1$, but thicker materials, such as those used as substrates, will have $F \ll 1$.

Strokhendl et al. have applied this method to study $10 \mu \mathrm{m}$ thick $\mathrm{C}_{60}$ films on $1 \mathrm{~mm}$ thick $\mathrm{CaF}_{2}$ substrates and $3.1 \mu \mathrm{m}$ thick $\mathrm{C}_{70}$ films on $1.49 \mathrm{~mm}$ thick fused silica substrates. ${ }^{25-28}$ They showed that for the 3.1-10 $\mu \mathrm{m}$ thick films, $F \approx 1$, and $F \approx 0$ for the $1-1.49 \mathrm{~mm}$ thick substrates. The substrate's contribution to the $I_{6}$ signal did not need to be considered because its phase-mismatched signal amplitude was $\sim 1 \%$ of the film's phase-mismatched signal amplitude. ${ }^{27}$

Greater attention must be given to the phase-mismatched signals of the substrate when very thin films are studied. The ITO films measured in this study are $20-30 \mathrm{~nm}$ thick. Here we show that a careful analysis of the dependence of $F$ on the angle $\theta$ and laser frequency $\omega$ allows the model described by Eq. (3) to be applied to the study of such films.

The dependence of factor $F$ on the laser wavelength is illustrated by the plot shown in Fig. 2(a). The $F$ values were 

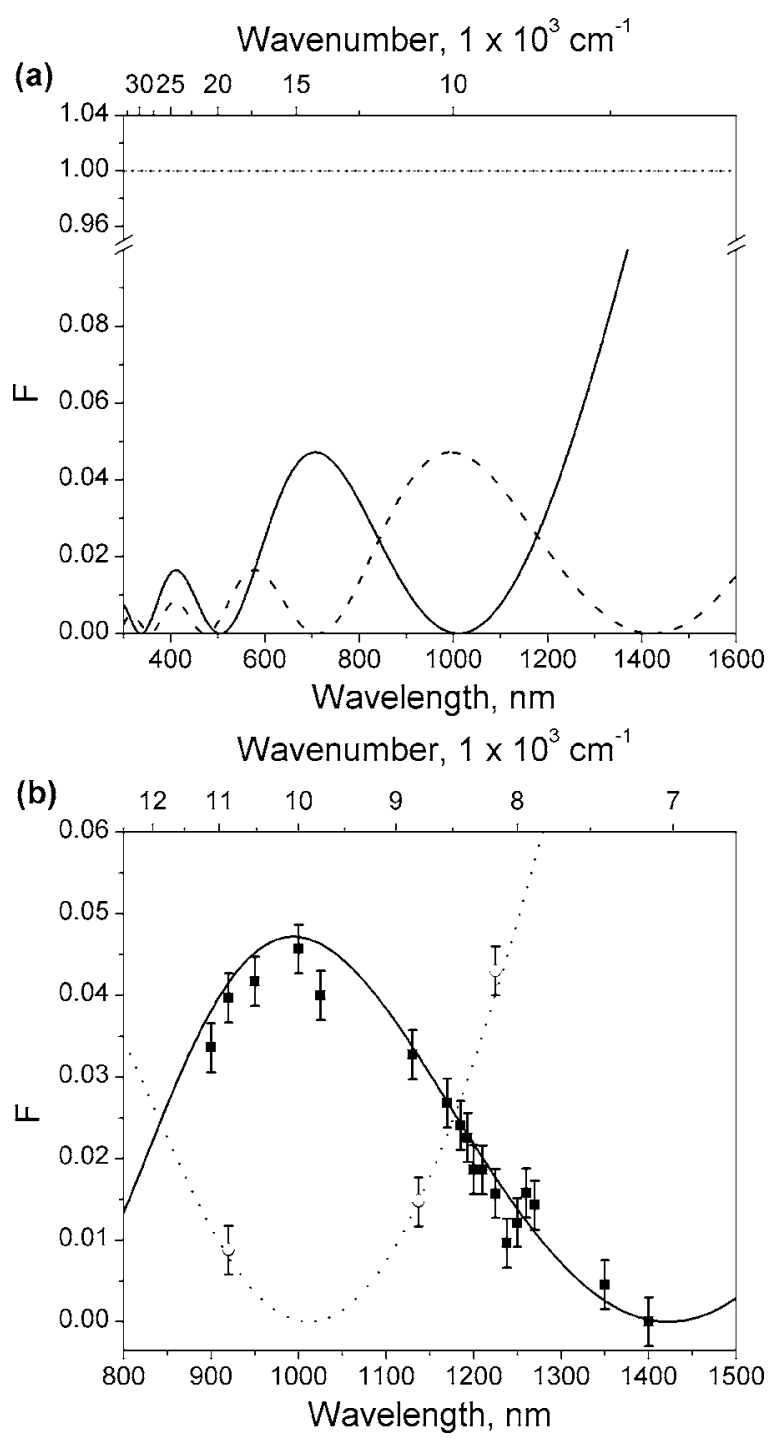

FIG. 2. (a) Factor $F$ values calculated using Eq. (4) for a $20 \mathrm{~nm}$ thick film $\left(\cdots, \theta=2.7^{\circ}\right.$ or $3.2^{\circ}$, lines overlap) and for a $0.7 \mathrm{~mm}$ thick substrate $(-, \theta$ $=2.7^{\circ}$ and,$--- \theta=3 \cdot 2^{\circ}$ ). (b) Experimental (symbols) and calculated (lines) $F$ values for $0.7 \mathrm{~mm}$ thick silica substrates. The angles used in the experiments are $\theta=3.2^{\circ}(\mathbf{\square})$ and $\theta=2.7^{\circ}(\bigcirc)$.

calculated using Eq. (4). The $20-30 \mathrm{~nm}$ thick ITO films have an $F \approx 1$, and the $0.7 \mathrm{~mm}$ glass substrate has $F \ll 1$ from 350 to $1600 \mathrm{~nm}\left(28500-6250 \mathrm{~cm}^{-1}\right)$. When $\theta=2.7^{\circ}$, the plots in Fig. 2(a) indicate that $F<0.015$ from 900 to $1200 \mathrm{~nm}\left(11000-8300 \mathrm{~cm}^{-1}\right)$. An angle of $\theta=3.2^{\circ}$ will provide the same reduction in the glass substrate signal for measurements at $1200-1500 \mathrm{~nm}\left(8300-6700 \mathrm{~cm}^{-1}\right)$.

A comparison of Eqs. (2) and (3) shows that the value of factor $F$ can be determined experimentally. By taking the ratio of the amplitudes of $I_{6}$ and $I_{4}$,

$$
F=\frac{I_{6}}{I_{4}}
$$

the experimental results can be compared to the calculated values as shown in Fig. 2(b). The agreement between the calculated and experimental $F$ values confirms that Eq. (3) accurately describes the intensity of the phase-mismatched DFWM signals of thick substrates. Because $F$ depends on

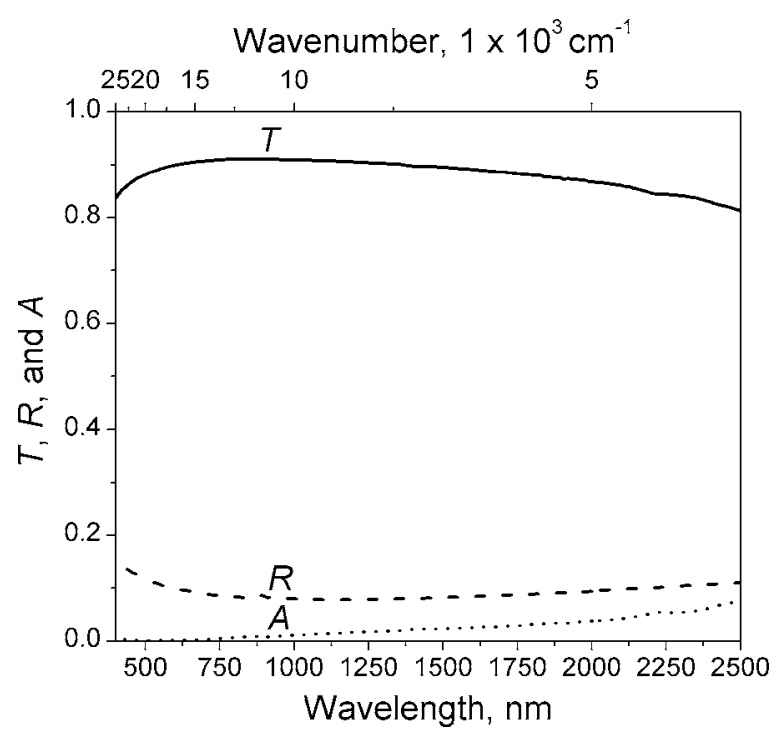

FIG. 3. Transmission $T(-)$, reflectance $R(---)$, and absorption $A(\cdots)$ spectra of ITO films used in nonlinear optical experiments.

both the beam angle and laser wavelength, Eq. (4) can be used to select an angle that will provide the optimal reduction of glass substrate's phase-mismatched DFWM signals over a particular spectral region. As shown in Fig. 2(b), optimal reduction of the substrate signal in the spectral region of our studies on $20 \mathrm{~nm}$ thick ITO films is provided by angles of $\theta=3.2^{\circ}$ (with the wavelength range of $1200-1500 \mathrm{~nm}$ ) and $\theta=2.7^{\circ}$ (at $900-1200 \mathrm{~nm}$ ).

\section{RESULTS AND DISCUSSION}

Optical spectra. The ITO films used in our study had an optical transmittance of $85 \%-90 \%$ and reflectance of $\sim 10 \%$ at $400-2500 \mathrm{~nm}\left(25000-4000 \mathrm{~cm}^{-1}\right)$. Figure 3 shows the absorbance $(A)$, transmittance $(T)$, and reflectance $(R)$ spectra of the film. (Absorbance values were obtained from $A$ $+T+R=1$.) The spectra in Fig. 3 are similar to those reported for $40 \mathrm{~nm}$ thick ITO films. ${ }^{18}$ In particular, the plasma frequency $\omega_{p}$, defined by the condition $T=R$, does not occur in this wavelength range. It is expected that $\omega_{p} \approx 2500 \mathrm{~cm}^{-1}$ $(4000 \mathrm{~nm})$ for the ITO films studied here based on the reported spectra. ${ }^{17,18}$

Determination of the nonlinear susceptibility spectrum. As described above, we measured the phase-mismatched DFWM signals to determine $\chi_{\text {ITO }}^{(3)}$ Measurements were performed using beam angles of $\theta=3.2^{\circ}$ and $\theta=2.7^{\circ}$. The use of two angles allows the nonlinear susceptibility of the ITO thin films to be characterized over a broad wavelength range. The $\chi^{(3)}$ Iто values were determined by comparing the amplitudes of the phase-mismatched DFWM signal of the

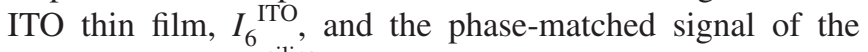
silica reference, $I_{4}$ silica,

$$
\left|\chi_{\text {ITO }}^{(3)}\right|=\left|\chi_{\text {silica }}^{(3)}\right| \sqrt{\frac{I_{6}{ }^{\text {ITO }}}{I_{4}{ }^{\text {silica }}}} \frac{l_{\text {silica }}}{l_{\text {ITO }}} \frac{n_{\text {ITO }}^{2}}{n_{\text {silica }}^{2}},
$$

with $n_{\mathrm{ITO}}=2.0,{ }^{17} l_{\mathrm{ITO}}=20 \mathrm{~nm}, n_{\text {silica }}=1.46, l_{\text {silica }}=1.0 \mathrm{~mm}$, and $\chi_{\text {silica }}^{(3)}=2.04 \times 10^{-22} \mathrm{~m}^{2} \mathrm{~V}^{-2}\left(1.46 \times 10^{-14} \mathrm{esu}\right){ }^{29}$ The $\chi_{\text {IтO }}^{(3)}{ }_{\text {ITO }}$ spectra are shown in Fig. 4 . The $I_{6}{ }^{\text {ITO }}$ signals used to 


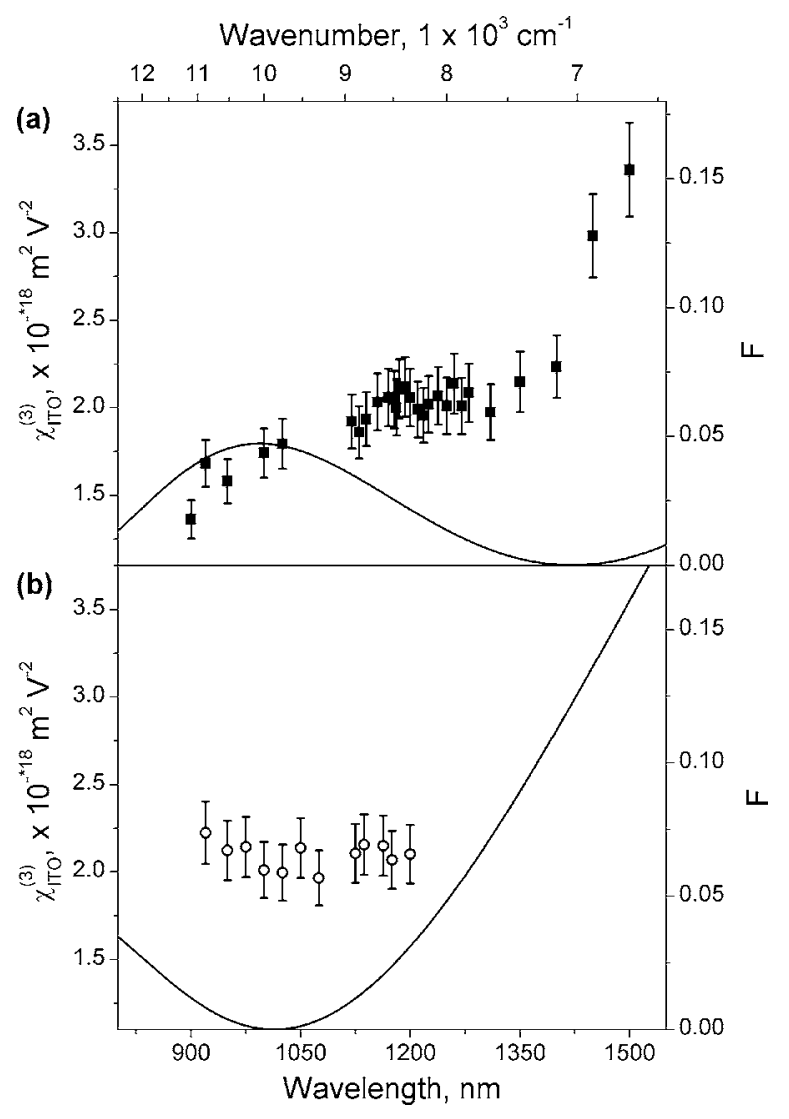

FIG. 4. $\chi^{(3)}$ ITO spectra measured with $\theta=3.2^{\circ}$ (a) and $\theta=2.7^{\circ}$ (b). The contributions from the substrate to the nonlinear spectra are indicated by the solid lines. The solid lines are plots of Eq. (4) that are normalized to the $\chi_{\text {ITO }}^{(3)}$ spectra based on the amplitudes of the phase-mismatched signals for the glass substrate and the ITO film measured under identical conditions.

generate the $\chi^{(3)}$ spectra shown in Figs. 4(a) and 4(b) may have contributions from the glass substrate. Because of the interference between the ITO film signal with that of the glass substrate, the separation of substrate's contribution to the ITO film signal needs to be carefully considered. To perform this analysis, contributions to the $\chi_{\text {ITO }}^{(3)}$ spectra from the glass substrate are indicated as solid lines in Figs. 4(a) and 4(b) [calculated using Eq. (4)].

The data in Fig. 4(a) show that the small contributions from the substrate allow the $\chi^{(3)}$ values found at $\lambda$ $>1200 \mathrm{~nm}\left(<8300 \mathrm{~cm}^{-1}\right)$, with $\theta=3.2^{\circ}$ to be attributed to the ITO film. At $\lambda<1200 \mathrm{~nm}\left(>8300 \mathrm{~cm}^{-1}\right)$ there is a significant contribution from the glass substrate. This contribution prevents the susceptibility values determined at these wavelengths from being unambiguously assigned to the ITO film. The substrate signal is actually larger than the signal from the ITO coated slide at $\lambda<1000 \mathrm{~nm}\left(<10000 \mathrm{~cm}^{-1}\right)$. This could be the result of destructive interference between the film and substrate signals. (The extent of the interference depends on the phase difference between the two components. $)^{27}$ Therefore, only $\chi_{\text {IтO values measured at }}^{(3)}$ $\lambda>1200 \mathrm{~nm}\left(>8300 \mathrm{~cm}^{-1}\right)$ with $\theta=3.2^{\circ}$ are used in the analysis of the nonlinear optical properties of ITO.

The region between $900-1100 \mathrm{~nm}\left(11000-9000 \mathrm{~cm}^{-1}\right)$ is better characterized using $\theta=2.7^{\circ}$ [Fig. 4(b)]. Under these conditions, the susceptibility spectrum only reflects the properties of the ITO film.

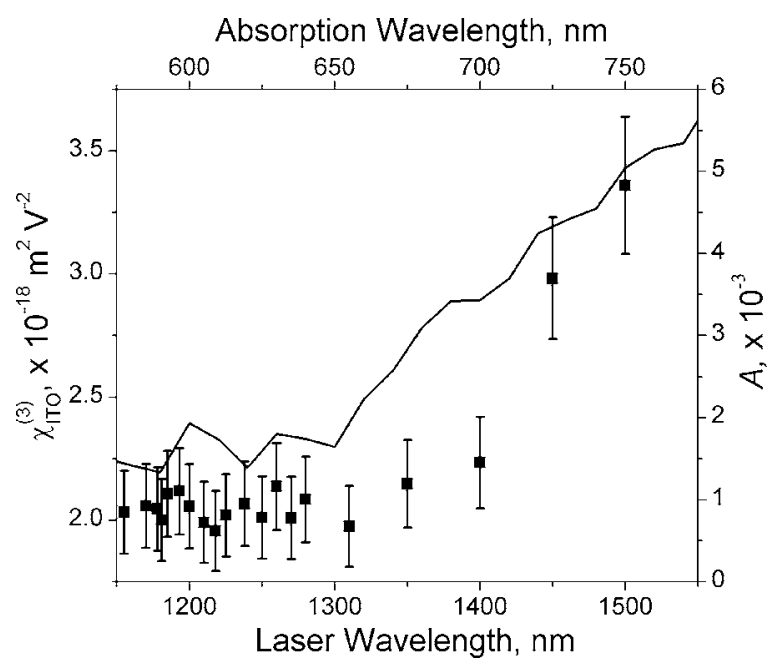

FIG. 5. Comparison of $\chi^{(3)}$ Iто ( $\square$ ) and absorption (-) spectra for ITO films. Two-photon absorption effects are considered here by showing the linear absorption spectrum (top scale) at two times higher energy than that of the DFWM spectrum (bottom scale).

Analysis of the ITO nonlinear susceptibility spectrum. The composite $\chi^{(3)}$ IтO spectrum is shown in Fig. 5. The spectrum only includes susceptibilities measured at wavelengths where $I_{6}{ }^{\text {ITO }}$ was at least two times larger than $I_{6}{ }^{\text {glass }}$. The ITO film has an essentially constant nonlinear susceptibility from 900 to $1300 \mathrm{~nm}\left(11000-7700 \mathrm{~cm}^{-1}\right)$, with the value of $\chi_{\text {IтO }}^{(3)}=(2.16 \pm 0.18) \times 10^{-18} \mathrm{~m}^{2} \mathrm{~V}^{-2}$. The $\chi_{\text {ITO }}^{(3)}$ begins to increase around $1300 \mathrm{~nm}\left(7700 \mathrm{~cm}^{-1}\right)$ and reaches $\chi_{\text {ITO }}^{(3)}$ $=(3.36 \pm 0.28) \times 10^{-18} \mathrm{~m}^{2} \mathrm{~V}^{-2}$ at $1500 \mathrm{~nm}\left(6700 \mathrm{~cm}^{-1}\right)$. The mechanism of nonlinear polarizability can be determined by comparing the $\chi^{(3)}$ ITO spectrum to the linear absorption spectrum. This analysis allows both one- and two-photon absorption effects to be considered.

First, we consider if one-photon absorption makes significant contributions to the $\chi_{\text {Iто }}^{(3)}$ spectrum. There is weak one-photon absorption over the entire spectral region used in the DFWM experiments (Fig. 3). This absorption increases from 0.015 at $1150 \mathrm{~nm}\left(8700 \mathrm{~cm}^{-1}\right)$ to 0.022 at $1500 \mathrm{~nm}$ $\left(6700 \mathrm{~cm}^{-1}\right)$. This gradual rise is different from the sharp increase at $1300 \mathrm{~nm}\left(7700 \mathrm{~cm}^{-1}\right)$ observed in the $\chi_{\text {ITO }}^{(3)}$ spectrum. This difference suggests that one-photon effects do not make significant contributions to the nonlinear polarization of ITO from 900 to $1500 \mathrm{~nm}\left(11000-6700 \mathrm{~cm}^{-1}\right)$.

Two-photon absorption, which is a third-order nonlinear process, could also contribute to the $\chi_{\text {ITO }}^{(3)}$ spectrum. To evaluate the contributions from two-photon absorption, the $\chi^{(3)}{ }_{\text {Iто }}$ spectrum must be compared to the absorption spectrum at twice the laser energy (for example, a two-photon transition to a state at $750 \mathrm{~nm}$ would require the absorption of two $1500 \mathrm{~nm}$ photons). This comparison is shown in Fig. 5. The $\chi_{\text {Iто }}^{(3)}$ and absorption spectra have similar features when compared in this manner. The sharp increase in absorption at $650 \mathrm{~nm}\left(15400 \mathrm{~cm}^{-1}\right)$ is similar to the increase in the nonlinear susceptibility at $1300 \mathrm{~nm}\left(7700 \mathrm{~cm}^{-1}\right)$. The spectra are also similar in that both the absorption and the $\chi^{(3)}$ ITO values are essentially constant at lower energies. These similarities suggest that the two-photon absorption contributes to the nonlinear susceptibility of the ITO films in the near IR. 
The above analysis allows the different regions of the $\chi_{\text {IтO }}^{(3)}$ spectrum to be attributed to a particular nonlinear polarization mechanism. We attribute the 900-1300 nm (11 $\left.000-7700 \mathrm{~cm}^{-1}\right)$ region of the spectrum to the nonresonant polarization. This polarization is most likely due to free electrons in the conduction band. The ultrafast time response discussed below supports this assignment. The increase in $\chi_{\text {Iто }}^{(3)}$ at $\lambda>1300 \mathrm{~nm}\left(7700 \mathrm{~cm}^{-1}\right)$ is attributed to twophoton absorption by the bulk plasmon. (Measurements of ITO prepared under various conditions have shown that the surface plasmon appears at much lower energies; ${ }^{19}$ therefore there is likely no significant contribution from the surface plasmon in the $\chi^{(3)}$ Iто spectrum.)

The $\chi^{(3)}$ Iто values found here are comparable to the nonlinear susceptibilities found for other semiconductor thin films. For example, a $55 \mathrm{~nm}$ thick film of $\mathrm{ZnO}$ microcrystallites was found to have $\chi^{(3)}$ values ranging from 1.4 $\times 10^{-16}$ to $1.4 \times 10^{-14} \mathrm{~m}^{2} \mathrm{~V}^{-2}\left(1 \times 10^{-8}-1 \times 10^{-6} \mathrm{esu}\right)$ when the excitation was at or near the exciton band edge. ${ }^{30} \mathrm{~A} \chi^{(3)}$ value of $1.8 \times 10^{-16} \mathrm{~m}^{2} \mathrm{~V}^{-2}\left(1.3 \times 10^{-8} \mathrm{esu}\right)$ was determined for an $80 \mathrm{~nm}$ thick amorphous $\mathrm{VO}_{2}$ film at $532 \mathrm{~nm}$ $\left.\left(18800 \mathrm{~cm}^{-1}\right)\right)^{31}$ The third-harmonic generation with the laser energy tuned to the absorption edge $(\sim 365 \mathrm{~nm})$ gave $\chi^{(3)}=3.8 \times 10^{-18} \mathrm{~m}^{2} \mathrm{~V}^{-2}\left(2.7 \times 10^{-11} \mathrm{esu}\right)$ for $\mathrm{GaN}$ films on sapphire substrates. ${ }^{32}$

The nonlinear optical properties of organic thin films have also been investigated. The $\chi^{(3)}$ spectrum of $\mathrm{C}_{70}$ was measured from 740 to $1600 \mathrm{~nm}\left(13500-6250 \mathrm{~cm}^{-1}\right)$ using DFWM with femtosecond pulses. ${ }^{26}$ The $\chi^{(3)}$ values ranged from $2.37 \times 10^{-20} \mathrm{~m}^{2} \mathrm{~V}^{-2}\left(1.7 \times 10^{-12} \mathrm{esu}\right)$ at $1500 \mathrm{~nm}$ to $\sim 7 \times 10^{-20} \mathrm{~m}^{2} \mathrm{~V}^{-2}\left(5 \times 10^{-12} \mathrm{esu}\right)$ at $1000 \mathrm{~nm}$. For an electropolymerized film of $\mathrm{Mn}(\mathrm{III})-5,10,15,20$-tetrakis-(4hydroxytetraphenyl)porphyrins $\left(\mathrm{Mn}^{3+} \mathrm{TPP}\right)$, we reported $\chi^{(3)}=1.36 \times 10^{-19} \mathrm{~m}^{2} \mathrm{~V}^{-2}$ at $1200 \mathrm{~nm}^{21}$ At the telecommunications wavelength of $1500 \mathrm{~nm}\left(6700 \mathrm{~cm}^{-1}\right)$, the optical nonlinearity of ITO is about 150 times bigger than that of the $\mathrm{C}_{70}$ film and about 25 bigger than that of the $\mathrm{Mn}^{3+}$ TPP electropolymerized film.

Polarization relaxation in ITO thin films. Several DFWM kinetics are shown in Figs. 6(a)-6(c). The ultrafast nonlinear response supports our assignment of the major nonlinear mechanism to nonresonant electronic polarization of free carriers (electrons) in the ITO conduction band. In addition, each of the kinetics has a slower component which increases in amplitude at longer wavelengths. A deconvolution assuming a Gaussian laser pulse shape was used to analyze these data. ${ }^{33}$ When single exponential relaxation was assumed, the deconvolution yielded lifetimes of $\tau_{\text {DFMW }}$ $=53 \mathrm{fs}$ at $1200 \mathrm{~nm} \quad\left(8300 \mathrm{~cm}^{-1}\right), \quad 84 \mathrm{fs}$ at $1300 \mathrm{~nm}$ $\left(7700 \mathrm{~cm}^{-1}\right)$ and $1450 \mathrm{~nm}\left(6900 \mathrm{~cm}^{-1}\right)$, and $130 \mathrm{fs}$ at $1500 \mathrm{~nm}\left(6700 \mathrm{~cm}^{-1}\right)$.

The DFWM signal, as expressed by Eq. (2), is proportional to the square of material's $\chi^{(3)}$ value. Therefore, the lifetime that describes material's relaxation is $\tau=2 \tau_{\mathrm{DFWM}}$. All lifetimes determined using this approach are summarized in Fig. 6(d).

Several mechanisms could contribute to the femtosecond relaxation observed in the kinetics in Fig. 6. The tail in the DFWM kinetics could be due to electron scattering in the

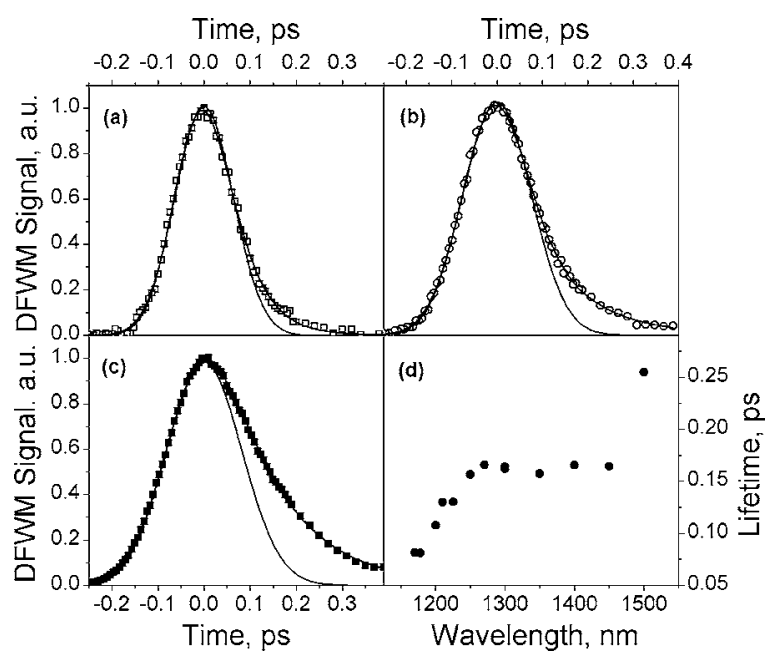

FIG. 6. Phase-mismatched DFWM kinetics at $1200 \mathrm{~nm}(\mathrm{a}), 1300 \mathrm{~nm}$ (b), and $1500 \mathrm{~nm}(\mathrm{c})$. A Gaussian function representing a $110 \mathrm{fs}$ laser pulse is shown for comparison in each plot. A solid line represents fitting (deconvolution) results obtained assuming a Gaussian laser pulse shape and a single exponential decay. (d) Lifetimes of the exponential component from 1125 to $1500 \mathrm{~nm}(\mathbf{O})$.

ITO conduction band. The Drude free electron model used to describe the electrical and optical properties of ITO thin films relates the plasma frequency $\omega_{p}$ to the electron scattering time $\tau^{34}$

$$
\omega_{p}=\sqrt{\frac{1}{R l \varepsilon_{0} c^{2} \tau}},
$$

where $R$ is the electrical resistance of the material, and the other parameters were defined above. A lifetime of $162 \mathrm{fs}$ (the average for the 1270-1450 nm kinetics) gives a $\lambda_{p}$ $=4166 \mathrm{~nm}\left(2400 \mathrm{~cm}^{-1}\right)$. As described above, $\lambda_{p}>2500 \mathrm{~nm}$ $\left(<4000 \mathrm{~cm}^{-1}\right)$ for the ITO thin films studied here, and the estimated $\lambda_{p} \approx 4000 \mathrm{~nm}\left(2500 \mathrm{~cm}^{-1}\right)$ is in good agreement with the published values for ITO films of similar thickness. ${ }^{17,18}$ Thus, the results are consistent with an assignment of the tail in the DFWM kinetics to electron scattering.

The wavelength dependence of the lifetime $\tau$, particularly the increase at $1500 \mathrm{~nm}$ [Fig. 6(d)], suggests that additional mechanisms may contribute to the femtosecond relaxation in the DFWM kinetics. More detailed studies are required to establish these mechanisms. In molecular systems, the one- and two-photon absorptions give rise to tails in DFWM kinetics similar to those in Fig. $6 .{ }^{24}$ If the increase in $\chi_{\text {тто }}^{(3)}$ at $1500 \mathrm{~nm}$ in Fig. 5 is attributed to two-photon absorption, then the longer lifetime at $1500 \mathrm{~nm}$ could be related to the relaxation of two-photon states.

\section{SUMMARY}

We have measured the nonlinear susceptibility spectrum of supported ITO films by using a DFWM technique based on the different phase-matching properties of thin films and thick substrates. The nonlinear response at $900-1300 \mathrm{~nm}$ $\left(11000-7700 \mathrm{~cm}^{-1}\right)$ is attributed to a nonresonant polarization of conduction band electrons. The $\chi^{(3)}$ ITO values increase at $\lambda>1300 \mathrm{~nm}\left(7700 \mathrm{~cm}^{-1}\right)$. The comparison of $\chi^{(3)}$ ITO and absorption spectra suggests that the enhancement may be due 
to a two-photon process. The DFWM kinetics have a femtosecond component at all of the wavelengths measured in our experiments. The lifetimes determined by deconvolution are consistent with the decay being due to electron scattering.

\section{ACKNOWLEDGMENTS}

The authors would like to thank Dr. Vidmantas Gulbinas for measuring the absorption and reflectance spectra, Dr. Gerdenis Kodis and Dr. Evaldas Katilius for the software used in the deconvolution analysis, and Hema Aluri and Dr. Maryanne Collinson for performing the AFM measurements. One of the authors (J.L.H.) acknowledges support from the VCU Graduate School Graduate Student Research Grant Program.

${ }^{1}$ I. Hamberg and C. G. Granqvist, J. Appl. Phys. 60, R123 (1986).

${ }^{2}$ M. Buchanan, J. B. Webb, and D. F. Williams, Appl. Phys. Lett. 37, 213 (1980).

${ }^{3}$ T. Maruyama and K. Fukui, J. Appl. Phys. 70, 3848 (1991).

${ }^{4}$ H. Kim, A. Pique, J. S. Horwitz, H. Mattoussi, H. Murata, Z. H. Kafafi, and D. B. Chrisey, Appl. Phys. Lett. 74, 3444 (1999).

${ }^{5}$ A. L. Dawar, A. K. Jain, C. Jagadish, and H. Hartnagel, Semiconducting Transparent Thin Films (Institute of Physics, Philadelphia, 1995)

${ }^{6}$ T. J. Gardner, C. D. Frisbie, and M. S. Wrighton, J. Am. Chem. Soc. 117 6927 (1995).

${ }^{7}$ C. Yan, M. Zharnikov, A. Goelzhaeuser, and M. Grunze, Langmuir 16, 6208 (2000).

${ }^{8}$ S. H. Brewer, D. A. Brown, and S. Franzen, Langmuir 18, 6857 (2002).

${ }^{9}$ F. Bedioui, J. Devynck, and C. Biedcharreton, Acc. Chem. Res. 28, 30 (1995).

${ }^{10}$ A. Bettelheim, B. A. White, S. A. Raybuck, and R. W. Murray, Inorg. Chem. 26, 1009 (1987).

${ }^{11}$ B. A. White and R. W. Murray, J. Electroanal. Chem. Interfacial Electrochem. 189, 345 (1985).
${ }^{12}$ C. W. Tang and S. A. VanSlyke, Appl. Phys. Lett. 51, 913 (1987).

${ }^{13}$ C. C. Wu, C. I. Wu, J. C. Sturm, and A. Kahn, Appl. Phys. Lett. 70, 1348 (1997).

${ }^{14}$ H. Ishii, K. Sugiyama, E. Ito, and K. Seki, Adv. Mater. (Weinheim, Ger.) 11, 605 (1999).

${ }^{15}$ J. Kido and Y. Iizumi, Chem. Lett. 1997, 963.

${ }^{16}$ J. Kido and Y. Iizumi, Appl. Phys. Lett. 73, 2721 (1998).

${ }^{17}$ H. Kim, C. M. Gilmore, A. Pique, J. S. Horwitz, H. Mattoussi, H. Murata, Z. H. Kafafi, and D. B. Chrisey, J. Appl. Phys. 86, 6451 (1999).

${ }^{18}$ H. Kim, J. S. Horwitz, G. Kushto, A. Pique, Z. H. Kafafi, C. M. Gilmore, and D. B. Chrisey, J. Appl. Phys. 88, 6021 (2000).

${ }^{19}$ P. F. Robusto and R. Braunstein, Phys. Status Solidi A 119, 155 (1990).

${ }^{20}$ G. R. Fowles, Introduction to Modern Optics (Rinehart, New York, 1968).

${ }^{21}$ J. L. Humphrey and D. Kuciauskas, J. Am. Chem. Soc. 128, 3902 (2006).

${ }^{22}$ J. Humphrey and D. Kuciauskas, J. Phys. Chem. B 108, 12016 (2004).

${ }^{23}$ P. N. Prasad and D. J. Williams, Introduction to Nonlinear Optical Effects in Molecules and Polymers (Wiley, New York, 1991).

${ }^{24}$ D. Kuciauskas, M. J. Porsch, S. Pakalnis, K. M. Lott, and M. E. Wright, J. Phys. Chem. B 107, 1559 (2003).

${ }^{25}$ F. P. Strohkendl, T. J. Axenson, R. J. Larsen, L. R. Dalton, R. W. Hellwarth, and Z. H. Kafafi, J. Phys. Chem. B 101, 8802 (1997).

${ }^{26}$ F. P. Strohkendl, T. J. Axenson, R. J. Larsen, L. R. Dalton, R. W. Hellwarth, and Z. H. Kafafi, Chem. Phys. 245, 285 (1999).

${ }^{27}$ F. P. Strohkendl, L. R. Dalton, R. W. Hellwarth, H. W. Sarkas, and Z. H. Kafafi, J. Opt. Soc. Am. B 14, 92 (1997).

${ }^{28}$ F. P. Strohkendl, R. J. Larsen, L. R. Dalton, and Z. K. Kafafi, Chem. Phys. Lett. 331, 354 (2000).

${ }^{29}$ D. Milam, Appl. Opt. 37, 546 (1998).

${ }^{30}$ W. Zhang, H. Wang, K. S. Wong, Z. K. Tang, G. K. L. Wong, and R. Jain, Appl. Phys. Lett. 75, 3321 (1999).

${ }^{31}$ H. Liu, S. Lysenko, A. Rua, V. Vikhnin, G. Zhang, O. Vasquez, and F. E. Fernandez, J. Lumin. 119-120, 404 (2006).

${ }^{32}$ J. Miragliotta and D. K. Wickenden, Phys. Rev. B 50, 14960 (1994).

${ }^{33}$ The software used to perform the deconvolution analysis can be found at http://www.public.asu.edu/ laserlab/asufit/asufit.html (accessed June 2006).

${ }^{34}$ S. H. Brewer and S. Franzen, J. Phys. Chem. B 106, 12986 (2002). 